УДК 81.42

\title{
И.В. Пономарёва
}

\section{НАРУШЕНИЕ ПРИНЦИПОВ ВЕРБАЛЬНОГО ОБЩЕНИЯ КАК ПРИЗНАК ПСЕВДОКОММУНИКАЦИИ}

Целью статьи является изучение особенностей диалогической речи в ситуациях неэффективной коммуникации. Проведенное исследование позволяет осмыслить с лингвистической точки зрения процесс регулирования речевого поведения участников диалогической интеракции, углубляет знание о природе и особенностях речевой коммуникации. Нарушение принципов, регулирующих речевое общение, означает ухудшение коммуникативных свойств речи, несоблюдение границ личной сферы собеседника, неосторожность в области его частных интересов. Тем самым, нарушение принципов вербального общения подрывает нормальное, полноценное общение, создает дискомфорт, напряженность и непонимание, вносит недоверие и разлад в разговор, усугубляет противоречия, направляет общение в неблагоприятное русло, становится причиной неуспешной и даже несостоявшейся коммуникации, способствует формированию ситуаций псевдокоммуникативных контактов. Подобное общение складывается как процесс, но не результат и представляется неудачным, неэффективным, бесперспективным.

Ключевые слова: коммуникация, кооперация, вежливость, диалогическое взаимодействие, коммуникативная неэффективность, псевдокоммуникация.

DOI: $10.35634 / 2412-9534-2021-31-2-209-214$

Современная лингвистика все чаще обращается к проблеме неэффективности речевой коммуникации. Исходным моментом в исследовании данного феномена выступает понимание причин и факторов, обусловливающих неэффективный характер речевого взаимодействия.

Речевая деятельность и язык тесно взаимосвязаны. М. Хайдеггер называет язык «домом бытия» [12]. Владение словом относится к сущностным чертам человека и неразрывно связано с его разумностью, социальностью, моральностью, творческой силой и универсальностью. В.Е. Владыкин, вслед за мыслителями, разработавшими философию Слова, пишет о соотнесенности и сопряженности мысли и слова, об энергетике резонанса слова «изреченного» и слова «воспринятого». Всемогущество слова, его власть над людьми со всей определенностью и остротой ставит проблему великой ответственности «говорящего», «пишущего», «вещающего» [2].

Любое речевое событие, осуществляемое говорящим, представляет собой производство конкретного предложения (высказывания) в условиях реальной речевой коммуникации. Иллокутивная сила высказывания определяется как интенция, направленная на собеседника: то, что, согласно намерению, должно быть понято [14]. Понятие иллокутивной функции (инициативной или реактивной) характеризует отношения между речевыми ходами (репликами), образующими диалогическое единство. Более того, по мнению Л.П. Рыжовой, целеустановка говорящего придает речевому акту особую «действенную» интонацию [8, с. 179]. Как отмечает Т.Г. Владыкина, иллокутивность особенно характерна для тех языков, которые близки к традиционной культуре и неразрывно с ней связаны. В высказывании как адресованной реплике оказываются слиты по крайней мере три плана или аспекта информации: когнитивная информация о предмете речи, модальная информация об интенциях говорящего и прагматическая регулятивная информация, побуждающая адресата на предопределенное адресантом ответное действие [3].

Выделяя три типа коммуникации - когнитивную, интерактивную и экспрессивную - Ю. Хабермас выводит понятие «идеальной речевой ситуации» [11], когда коммуниканты имеют равные возможности участия в диалоге, могут открыто обозначать свои позиции, выражать свои мысли, критиковать чужие идеи. Согласно автору, единственной мотивацией коммуникативных партнеров должно выступать достижение консенсуса по поводу истинности высказываний и валидности норм. Любое нормальное использование языка предполагает диалогичность, любой дискурс строится коллективно, значение любого высказывания является результатом совместной - диалогической - деятельности. Взаимодействие представляет собой коллективную деятельность по созданию смысла, так как «смысл рождается во взаимодействии» собеседников [10, p. 18].

Являясь субъектом социального взаимодействия, «существом, ощущающим свою связь с прошлым, переживающим настоящее и устремленным в будущее» [4, с. 13], человек живет не в мире 
изолированных световых или цветовых пятен, звуков или прикосновений. Он живет в мире вещей, предметов и форм, в мире сложных ситуаций [5, с. 121]. Человек всегда предстает как выразитель социальных установок, запечатлевающихся в его ценностной и мировоззренческой ориентации; он «немыслим вне конкретного общественного окружения» [4, с. 16].

Коммуникативный процесс как разновидность целенаправленной деятельности представляет собой сложную и неоднородную систему, функциональные и материальные компоненты которой весьма разнообразны. Коммуникация как целенаправленная активность человека основана на намеренном использовании языка, являющегося компонентом информационно-когнитивной системы, в которой взаимодействуют мышление, сознание, память и язык, и основным назначением которой является обеспечение процессов восприятия, понимания, переработки информации и, соответственно, адекватной на нее реакции. Особое внимание уделяется говорящему человеку, личности, личностным факторам языкового общения, а также отражению этих факторов в языковых структурах (в дискурсе).

В общении особую значимость приобретают: умение устанавливать и поддерживать контакт; избегать конфликта как «сознательного совершения одной стороной в ущерб другой стороне речевых действий, выражающихся в форме упрека, замечания, возражения, обвинения, угрозы, оскорбления и т.д.» [7, с. 231]; достигать компромисса как «тактики взаимного приспособления, предполагающей изменение способов поведения» [1, с. 491]; сохранять гармонию как «важнейший руководящий принцип в повседневной жизни» [6, с. 361]. Гармонизации общения способствуют также коммуникативная заинтересованность, коммуникативная компетентность, коммуникативная культура личности, адекватная самооценка и оценка партнера, умение произвести впечатление на собеседника,

Основу успешного диалогического общения, несомненно, составляет соблюдение основополагающих принципов речевого взаимодействия: принципа кооперации и принципа вежливости. Принцип кооперации (П. Грайс) характеризует порядок совместного оперирования информацией и взаиморасположение говорящих в структуре коммуникативного акта. Принцип коммуникативного сотрудничества выступает как общее условие интеракции, осуществляемой в соответствии с правилами поведения (конверсационными максимами) [9], определяющими то, что участники интеракции должны делать, чтобы действовать осмысленно, разумно, рационально, понятно [8, с. 194]. Основное требование, которого должны придерживаться все участники диалога с целью максимально эффективной передачи информации, звучит: Твой вклад на данном шаге диалога должен быть таким, какого требует совместно принятая иель этого диалога. Данный принцип включает: 1) постулат количества: Твое высказывание должно содержать информации не меньше и не больше, чем требуется (для выполнения текущих целей диалога); 2) постулат качества: Не говори того, что тыл считаешь ложным, и того, для чего у тебя нет достаточных оснований; 3) постулат отношения: Не отклоняйся от темы; 4) постулат способа: Избегай непонятных выражений и неоднозначности, будь краток и организован.

Нарушение принципа кооперации означает коммуникативную незаинтересованность, ненастроенность на мир собеседника, разобщенность действий, неситуативность речевого поведения, несогласованность планов и схем речевого поведения собеседников, отсутствие обратной связи и понимания.

Примером нарушения принципа коммуникативного сотрудничества служит отрывок из пьесы Б. Шоу «Heartbreak house», представляющий общение двух встретившихся после долгой разлуки сестер, леди Этеруорд (А) и миссис Хэшебай (Б), между которыми происходит следующий диалог:

Lady Utterword: Is it possible that you don't know me? (1)

Mrs. Hushabye: Of course, I remember your face well. Where have we met? (1a)

Lady Utterword: Didn't father tell you I was here? Oh! This is really too much. (2)

Mrs. Hushabye: Papa? (2a)

Lady Utterword: Yes, papa. Our papa. You unfeeling wretch. I'll go straight to a hotel! (3)

Mrs. Hushabye: Gracious goodness! You don't mean to say that you are Addy? (3a)

Lady Utterword: I certainly. Am Addy and I don't think I can be so changed that you would not have recognized me, if you had any real affection for me. (4)

Mrs. Hushabye: You do look as well. You are much handsomer than you used to be. (4a)

Lady Utterword: Hesione, are you going to kiss me or are you not? (5)

Mrs. Hushabye: What do you want to be kissed for? (5a)

Lady Utterword: I don't want to be kissed; but I do want you to behave properly and decently. We are sisters. We have been separated for twenty-three years. You ought to kiss me. (6) 
Нарушение принципов вербального общения как признак псевдокоммуникации

Mrs. Hushabye: Tomorrow morning, dear, before you make up. I hate the smell of powder. (6a) Lady Utterword: Oh! You unfeeling... (7) [16].

Неадекватность речевого поведения миссис Хэшебай проявляется в отказе от контакта, нежелании проявлять интерес к предлагаемой теме, игнорировании инициатив собеседницы: девушка делает вид, что не узнает сестру (1a), вместо ответа задает встречный вопрос, выражает недоумение, продолжает делать вид, что не узнает сестру (2a), насмехается над сестрой, начинает наконец «признавать» ее (3a), продолжает насмехаться над собеседницей, неожиданно «признает» сестру и даже восхищается ее внешним видом (4a), посредством риторического вопроса косвенно отказывается выполнить просьбу сестры (5a), косвенно отказывается общаться в доброжелательном тоне: обещает выполнить просьбу сестры, однако при определенных обстоятельствах (6а).

Собеседница миссис Хэшебай, леди Этеруорд (инициатор общения), делает неоднократные попытки установить контакт: выражает недоумение и досаду по поводу неожиданной холодности сестры (1), пытается выяснить причину «забывчивости» сестры (2), предпринимает сложный речевой ход: напоминает сестре об их родственной связи, возмущается бесчувственностью сестры, выражает намерение покинуть дом, в котором ей оказан такой холодный прием (3), пытается усовестить сестру насмешкой и вызвать эмоцию стыда (4), пытается пробудить в сестре родственные чувства, вызвать эмоцию радости (5), вновь предпринимает сложный речевой ход: возражает сестре, потом упрекает, напоминает о долгой разлуке, настаивает на проявлении родственных чувств (6); заключительный речевой ход выступает выражением глубокого сожаления по поводу бездушности сестры (7).

Коммуникативный сбой в данном диалогическом фрагменте происходит вследствие нежелания одной из сестер соблюдать правила принципа коммуникативного сотрудничества: нарушение постулата качества и постулата отношения. Встреча сестер не принесла радости им обеим: одна выслушала упреки сестры по поводу своей бесчувственности, другая испытала огорчение от недоброжелательности родного человека.

Нарушение диалогического взаимодействия происходит: на коммуникативном уровне - несовпадение интенций и стратегий говорящих; неситуативность речевого поведения; несоответствие смысловых позиций собеседниц, несогласованность тематического содержания реплик собеседниц: реплики А - попытка установить контакт, призыв к сближению, к проявлению родственных чувств, реплики Б - нежелание общаться на предлагаемую тему, отказ от общения; на интерактивном уровне отсутствие диалогичности, действия собеседниц не направлены на соотнесение целей каждой из сторон и организацию их достижения, отсутствие взаимовлияния коммуникантов, отсутствие связи между речевыми ходами: реакции Б не соответствуют стимулам А; на периептивном уровне - несовпадение особенностей мировоззрения, ненастроенность на мир собеседника, рассогласованность эмоционального состояния и речевого поведения.

Принции вежливости (Р. Лакофф, Дж. Лич) определяет целый ряд прагматических правил ведения разговора: соблюдение границ личной сферы собеседника и осторожность в области его частных интересов; необременение собеседника, предохраняющее коммуникантов от доминирования в ходе речевого акта; позитивность в оценке других; реалистическая самооценка; недопустимость самовосхваления и самолюбования; неоппозиционность, то есть поиск согласия с целью продуктивного завершения речевого акта; уход от конфликта, благожелательность и взаимные уступки. Следование принципу вежливости накладывает определенные ограничения на поведение коммуникантов: необходимость учитывать интересы партнера, считаться с его мнением, желаниями чувствами, облегчать задачи, возлагаемые на него в процессе коммуникации. Данный принцип включает [13]: 1) максиму такта: Сведи к минимуму издержки для другого и сделай максимальной пользу для другого (соблюдение границ личной сферы собеседника и дистанции между коммуникантами, осторожность в отношении речевой стратегии в области частных интересов собеседника): 2) максиму великодушия: Сведи к минимуму пользу для себя и максимально увеличь пользу для других (необременение собеседника, недопустимость доминирования в ходе речевого акта); 3) максиму одобрения: Сведи к минимуму порицание другого и сделай максимальной похвалу другого (позитивность в оценке собеседника); 4) максиму скромности: Сведи к минимуму восхваление себя самого и доведи до максимума порицание в адрес самого себя (неприятие похвал в собственный адрес, реалистическая, объективная самооценка); 5) максиму согласия: Сделай минимальным несогласие между собой и другим и добейся максимального согласия между собой и другим (отказ от конфликта, поиск согласия); 6) максиму симпатии (благожелательность, создающую благоприятный фон для перспективного предметного 
разговора и предохраняющую речевые акты от конфликта): Сведи к минимуму антипатию между собой и другим; добейся максимальной симпатии между собой и другим (благожелательность, этикетные вопросы о жизни, делах, здоровье). Несоблюдение принципа вежливости означает незнание или игнорирование коммуникативных норм этикетного речевого общения, нежелание расположить к себе коммуникативного партнера, неадекватная тональность общения, несогласованность эмоционального состояния.

Представляет интерес диалогический фрагмент из повести В. Шукшина «Печки-лавочки», демонстрирующий ситуацию общения двух людей: Ивана Расторгуева, направляющегося с женой на отдых к морю, и его соседа по купе, командировочного, который сразу решил для себя, что с сельскими жителями можно не церемониться, говорить снисходительно, насмехаться, делать замечания:

- Деревенские свои замашки надо оставлять дома. Раз уж поехали... к югу, как выражаешься, надо соответственно и вести себя. Или уж сиди дома, не езди. А куда к югу-то? Юг большой... (1)

- На кудыкину гору. Сльхали такую? (1а)

- A ты что это сразу в бутылку-то полез? (2)

- А вы что это сразу тыкать-то начали? (2a)

- О-о! Да мыл, оказывается, с гонором! (3)

- Вот так, дорогой товарищ. Я бы лучше эти ваши ухмылочки не строил. Что, вы от этого сильно умный стали? Нет же... (3a).

- Слушайте! Bы это, научитесь вести себя как положено - вы же не у себя в деревне. Еще жену с собой тянет. (4)

- А что тебе моя жена? (4a)

- Надо сначала самому научиться ездить. Потом уж жену за собой возить. (5)

- А твое какое дело? Я тебе что, на хвост нечаянно наступил? (5а)

- Да вы только не стройте из себя... Видели мы и таких. И всяких. А то ведь как сел, так и слезть можешь. (6)

- Профурсетка в штанах. Сам у меня слезешь. И по шпалам, по шпалам... (6а) [15]

Коммуникативные нарушения в представленном диалогическом фрагменте обусловлены неадекватностью речевого поведения командировочного. Его речевые действия представлены: (1) экспозитивными высказываниями, смысловая нагрузка которых заключается в попытке самовыразиться и самоутвердиться, показать свое социальное превосходство; (2) неоднократно повторяющимися высказываниями-суггестивами, смысловая нагрузка которых заключается не в предоставлении полезного совета или дельного наставления, а в намерении задеть, огорчить, обидеть собеседника.

Анализ речевых ходов командировочного свидетельствует о том, что он, делая замечания попутчику и говоря обидные слова («деревенские замашки» (1)), указывая собеседнику на место, которое тот, по его мнению, должен занимать (2), пытается показать свое социальное превосходство (3). Делая наставления Ивану («научитесь вести себя как положено») и говоря ему обидные слова («вы не у себя в деревне»), командировочный утверждает: «нельзя тебе сравниваться с городскими жителями» (4). Продолжая поучать Ивана, упоминая в разговоре о его жене, командировочный старается показать свое превосходство над сельским жителем (5). Понимая, что не справляется словесно и не может стать доминирующим в разговоре, он говорит обидные слова и применяет тактику угрозы (6); всем своим речевым поведением стремится задеть, обидеть, унизить собеседника. При этом ответы собеседника не принимаются во внимание: он их не слышит или не хочет слышать.

Собеседник командировочного, Иван Расторгуев, парирует речевые ходы командировочного: уклоняется от прямого ответа на оскорбление (1a), ставит командировочного на место, но старается быть вежливым (2a), указывает ему на недостойное поведение (3a), пытается утихомирить собеседника, показывает, что ни в чем ему не уступает (4a), искренне недоумевает по поводу неприятных, обидных замечаний (5a), наконец, в свою очередь называет командировочного обидным словом («профурсетка в штанах»), отвечает такой же угрозой («сам у меня слезешь»), с какой к нему обращается собеседник (6a).

Нарушение диалогического взаимодействия происходит: на коммуникативном уровне (нарушение принципов, регулирующих речевое общение, неинформативность сообщений); на интерактивном уровне (отсутствие связи между речевыми ходами: перехват инициативы, нарушение темы, игнорирование вопросов и инициатив собеседника); на перцептивном уровне (несовместимость эмоционального состояния, психологического настроя и мотивации действий). 
Проведенный в работе анализ диалогических фрагментов на коммуникативном уровне, отражающем коммуникативные характеристики диалогического дискурса и определяющем единство содержательной стороны диалогического взаимодействия, на интерактивном уровне, определяющем взаимосвязанность речевых действий в общении, и на периептивном уровне, связанном с личностными, социально-психологическими, эмоционально-экспрессивными характеристиками коммуникантов, показал, что псевдокоммуникация представляет собой феномен, характеризующийся совокупностью нарушений общих принципов коммуникативного взаимодействия, негативно влияющих на протекание коммуникативного процесса. Для ситуаций псевдокоммуникативных контактов характерны: отсутствие общей коммуникативной цели; нежелание / неумение обозначить свои коммуникативные позиции; нежелание / неумение понять и принять интенции собеседника; нежелание / неумение поддерживать высокий уровень заинтересованности собеседника; неумение / неготовность сотрудничать; отсутствие понимания необходимости конструктивного диалога; безучастность коммуникантов в едином процессе демонстрации и интерпретации смыслов.

\section{СПИСОК ИСТОЧНИКОВ И ЛИТЕРАТУРЫ}

1. Атватер И. Психология для жизни. Упорядочение образа мыслей, развитие и поведение человека наших дней. М.: ЮНИТИ-ДАНА, 2003. 535 с.

2. Владыкин В.Е. «Как слово наше отзовется...» (слово в системе этнокультурной информации) // Многоязычие в образовательном пространстве. Т. 5. Ижевск: Удмуртский университет, 2014. С. 329-340.

3. Владыкина Т.Г. Мифология визуального и акустического в коммуникативном поведении удмуртов // Вестник Удмуртского университета. Серия: История и филология. 2008. № 5. С. 82- 85.

4. Губман Б.Л. Смысл истории: очерки современных западных концепций. М.: Наука, 1991. 192 с.

5. Лурия А.Р. Лекции по общей психологии. СПб.: Питер, 2010. 326 с.

6. Мацумото Д. Психология и культура. СПб.: Питер, 2003. 718 с.

7. Пушина Н.И. Принципы коммуникации как фактор предупреждения коммуникативных неудач в межкультурном диалоге // Социальный мир человека. Вып. 6. Ижевск: ERGO, 2016. С. 231-235.

8. Рыжова Л.П. Французская прагматика. М.: КомКнига, 2007. 240 с.

9. Grice H.P. Logic and Conversation // Syntax and Semantics. New York: Speech Acts, 1975. Vol. III. P. 45-60.

10. Guespin L. Problématique des travaux sur le discours politique // Langage, 1971. № 23. P. 3-24.

11. Habermas J. The Theory of Communicative Action. Frankfurt am Main, 1987. 465 p.

12. Heidegger M. Being and Time. Oxford: MPG Books Ltd, 1999. 503 p.

13. Leech G.N. Principles of Pragmatics. London, 1983. 112 p.

14. Strawson P.F. Intention and Convention in Speech Acts // The Philosophical Review. 1964. № 4. P. 439-460.

15. Шукшин В. Печки-лавочки.. Собрание сочинений в 5 томах. Т. 3. Фрунзе: Книголюб, 1992. С. 227-291.

16. Show B. Heartbreak house. Moscow: Foreign languages. Publishing House, 1952. P. 149-151.

Поступила в редакцию 24.11.2020

Пономарёва Инна Владимировна, кандидат филологических наук, доцент

кафедры иностранных языков естественных факультетов

ФГБОУ ВО «Тверской государственный университет»

170100, Россия, г. Тверь, ул. Желябова, 33

E-mail: ivponomaryova@mail.ru

\section{I.V. Ponomaryova \\ INFRINGEMENT OF THE PRINCIPLES OF VERBAL COMMUNICATION AS A SIGN OF PSEUDOCOMMUNICATION}

DOI: 10.35634/2412-9534-2021-31-2-209-214

The purpose of the article is to study the features of dialogic speech in the situations of ineffective communication. The research allows us to comprehend from a linguistic point of view the process of regulation of the verbal behavior of the dialogical interaction participants, to deepen the knowledge of nature and features of verbal communication. The infringement of principles regulating verbal communication means deterioration of communicative properties of speech, violation of the boundaries of the interlocutor's personal sphere, carelessness in the field of the partner's private interests. Thereby verbal communication principles infringement destroys normal communication, makes discomfort, ten- 
sion and misunderstanding, introduces distrust and discord into the conversation, aggravates contradictions, directs communication in the unfavorable direction, becomes the cause of unsuccessful and even failed communication, contributes to the formation of the situations of pseudocommunicative contacts. The communication is made as a process but not a result therefore it is considered as unsuccessful and ineffective.

Keywords: communication, cooperation, politeness, dialogic interaction, communicative ineffectiveness, pseudocommunication.

\section{REFERENCES}

1. Atvater I. Psihologiya dlya zhizni. Uporyadochenie obraza myslej, razvitie i povedenie cheloveka nashih dnej. [Psychology for life. Streamlining the way of thinking, the development and behavior of a person today] M.: YUNITIDANA, 2003. 535 s. (In Russian).

2. Vladykin V.E. «Kak slovo nashe otzovetsya ...» (slovo v sisteme etnokul'turnoj informacii) [“How our word will respond ..." (a word in the system of ethnocultural information)] // Mnogoyazychie v obrazovatel'nom prostranstve. T. 5. Izhevsk: Izdatel'stvo «Udmurtskij universitet», 2014. S. 329-340. (In Russian).

3. Vladykina T.G. Mifologiya vizual'nogo i akusticheskogo v kommunikativnom povedenii udmurtov [Mythology of the visual and acoustic in the communicative behavior of the Udmurts] // Vestnik Udmurtskogo universiteta. Seriya: Istoriya i filologiya. 2008. № 5. S. 82- 85. (In Russian).

4. Gubman B.L. Smysl istorii: ocherki sovremennyh zapadnyh koncepcij. [The meaning of the history: essays on contemporary Western concepts] M.: Nauka, 1991. 192 s. (In Russian).

5. Luriya A.R. Lekcii po obshchej psihologii. [Lectures on general psychology] SPb.: Piter, 2010. 326 s. (In Russian).

6. Macumoto D. Psihologiya i kul'tura. [Psychology and culture] SPb.: Piter, 2003. 718 s. (In Russian).

7. Pushina N.I. Principy kommunikacii kak faktor preduprezhdeniya kommunikativnyh neudach $\mathrm{v}$ mezhkul'turnom dialoge [Principles of communication as a factor in preventing communication failures in intercultural dialogue] // Social'nyj mir cheloveka. Vyp. 6. Izhevsk: ERGO, 2016. S. 231-235. (In Russian).

8. Ryzhova L.P. Francuzskaya pragmatika. [French pragmatics] M.: KomKniga, 2007. 240 s. (In Russian).

9. Grice H.P. Logic and Conversation // Syntax and Semantics. New York: Speech Acts, 1975. Vol. III. P. 45-60. (In English).

10. Guespin L. Problématique des travaux sur le discours politique [Problematic of works on political discourse] // Langage, 1971. № 23. P. 3-24. (In French).

11. Habermas J. The Theory of Communicative Action. Frankfurt am Main, 1987. 465 p. (In English).

12. Heidegger M. Being and Time. Oxford: MPG Books Ltd, 1999. 503 p. (In English).

13. Leech G.N. Principles of Pragmatics. London, 1983. 112 p. (In English).

14. Strawson P.F. Intention and Convention in Speech Acts // The Philosophical Review, 1964. № 4. P. 439-460. (In English).

15. Shukshin V. Pechki-lavochki.. [Stoves and benches] Sobranie sochinenij v 5 tomah. T. 3. Frunze: Knigolyub, 1992. S. 227-291. (In Russian).

16. Show B. Heartbreak house. Plays. Moscow: Foreign languages. Publishing House, 1952. P. 149-161. (In English).

Received 24.11.2020

Ponomaryova I.V., Candidate of Philology, Associate Professor at Department of foreign languages for natural faculties Tver State University Zhelyabova st., 33, Tver, Russia, 170100

E-mail: ivponomaryova@mail.ru 